Regards sur l'économie allemande

Bulletin économique du CIRAC

$111 \mid 2013$

Varia

\title{
Relation franco-allemande
}

Allemagne - Les entreprises, moteurs de la relation franco-allemande?

\section{(2) OpenEdition}

\section{Journals}

Édition électronique

URL : http://journals.openedition.org/rea/4639

DOI : $10.4000 /$ rea.4639

ISSN : 1965-0787

Éditeur

CIRAC

Édition imprimée

Date de publication : 1 décembre 2013

Pagination : 40

ISSN : 1156-8992

Référence électronique

"Relation franco-allemande », Regards sur l'économie allemande [En ligne], 111 | décembre 2013, mis en ligne le 17 décembre 2013, consulté le 22 septembre 2020. URL : http://journals.openedition.org/ rea/4639; DOI : https://doi.org/10.4000/rea.4639

Ce document a été généré automatiquement le 22 septembre 2020

(c) CIRAC 


\title{
Relation franco-allemande
}

Allemagne - Les entreprises, moteurs de la relation franco-allemande?

\section{RÉFÉRENCE}

\author{
Allemagne - Les entreprises, moteurs de la relation franco-allemande ?, Histoire \\ d'Entreprises, $\mathrm{n}^{\circ}$ 11, Histoire d'Entreprises, Lyon, 2013, $104 \mathrm{p}$.
}

1 A l'occasion du 50 anniversaire du Traité de l'Elysée, la revue Histoire d'Entreprises propose un numéro spécial bilingue français/allemand. Dans une interview, Francis Mer, ministre de l'Economie, des Finances et de l'Industrie de 2002 à 2004, fondateur du Club économique franco-allemand en 2005 et actuellement vice-président du groupe Safran, revient sur l'évolution des relations économiques entre la France et l'Allemagne depuis la CECA. Suivent une analyse d'EADS signée par Henrik Uterwedde, directeur adjoint de l'Institut Franco-Allemand de Ludwigsburg (DFI), des portraits d'entreprises implantées dans le pays partenaire et des exemples de coopérations binationales réussies dans le domaine de l'industrie. Ce riche numéro fait également la part belle à la culture et au social, avec des articles sur la chaîne Arte, L'internationale Film-Union AG et l'histoire comparée des syndicalismes français et allemands, pour se clore sur un entretien instructif avec Jacques Pateau, expert en management interculturel. (sh) 